\title{
EXERCÍCIOS DE PENSAMENTO PARA NÃO SERMOS INDIFERENTES AO QUE FAZEMOS EM NOME DA FILOSOFIA NA ESCOLA ${ }^{1}$
}

\author{
José Teixeira Neto $^{2}$
}

Emerson Araújo De Medeiros ${ }^{3}$

\begin{abstract}
RESUMO
Fruto das discussões na disciplina Filosofia do Ensino de Filosofia no Mestrado Profissional em Filosofia (PROF-FILO - Núcleo da Universidade do Estado do Rio Grande do Norte-UERN/Campus Caicó-CaC), o presente artigo utiliza a metáfora da viagem e das paisagens com objetivo de apresentar o percurso da disciplina em questão e de discutir o ensino de filosofia a partir de alguns elementos filosóficos. Nesse percurso parte-se de uma compreensão subjetiva do que seja a filosofia, para, em seguida, abordar alguns direcionamentos à pergunta "O que é a filosofia?" em Martin Heidegger, José Ortega y Gasset e Gilles Deleuze e Félix Guattari. Após a análise dessas etapas descritas, o texto apresenta uma reflexão sobre o ensino da Filosofia no Ensino Médio na perspectiva de que não existe uma única postura ou filosófica ou pedagógica ou didática, mas uma orientação para o ensino-aprendizagem da filosofia depende inicialmente da perspectiva subjetiva adotada pelo filósofoprofessor; das condições objetivas e estruturais, por exemplo, da Escola e do espaço-lugar que permitimos aos alunos para eles mesmos possam filosofar.
\end{abstract}

Palavras-chave: Ensino de Filosofia. Ensino Médio. Filosofar. Sala de Aula. Escola.

\section{RIASSUNTO}

\footnotetext{
${ }^{1}$ Primeiramente apresentado ao componente curricular Filosofia do Ensino de Filosofia do PROF-FILO (Núcleo da UERN/Campus Caicó-CaC), esse artigo aparece aqui em uma nova versão revisada e modificada pelos autores que assinam o texto. Nele, podemos perceber a proposta do componente curricular e, ao mesmo tempo, o acontecimento da disciplina na trajetória do aluno do mestrado, professor-filósofo do Ensino Médio. Sobre a possibilidade de escrever a dois, escreve Deleuze: "Em todos os meus livros busquei a natureza do acontecimento; este é um conceito filosófico, o único capaz de destituir o verbo ser e o atributo. A esse respeito, escrever a dois torna-se perfeitamente normal. Basta que algo se passe, uma corrente só ela portadora de nome próprio. Mesmo quando se acredita escrever só, isto sempre se passa com algum outro que nem sempre é nomeável”. (DELEUZE, 2012, p. 181).

2 Professor Adjunto no Departamento de Filosofia da Universidade do Estado do Rio Grande do Norte-UERN, Campus Caicó-CaC e professor do Mestrado Profissional em Filosofia (PROF-FILO/UERN/Campus Caicó). E-mail: josteix@hotmail.com

${ }^{3}$ Mestre em Filosofia pelo Curso de Mestrado Profissional em Filosofia da Universidade do Estado do Rio Grande do Norte - UERN, Campus Caicó - CaC. Mestre em Teologia Moral Fundamental (Ciências humanas) pela Pontificia Università Gregoriana - Roma/Itália. Professor da Faculdade Católica Santa Teresinha e professor titular de Filosofia da Escola Estadual Prof. Antônio Aladim de Araújo-Caicó/RN. E-mail: emerson.caico@hotmail.com
} 
Il testo è il risultato delle discussioni nella disciplina Filosofia dell'insegnmento di Filosofia nel Mestrado Profissional em Filosofia (PROF-FILO Núcleo da Universidade do Estado do Rio Grande Norte-UERN/Campus Caicó-CaC). Si utilizza della metafora del viaggio e dei paesaggi al fine di introdurre la disciplina in questione e discutere l'insegnamento della filosofia da alcuni elementi filosofici. Questo percorso inizia da una comprensione soggettiva della filosofia, per poi affrontare alcune indicazioni per la domanda "che cosa è filosofia?" in Martin Heidegger, José Ortega y Gasset e Gilles Deleuze e Félix Guattari. Dopo l'analisi di questi paessaggi, il testo offrirà una riflessione sull'insegnamento della filosofia nei licei nella prospettiva che non esiste soltanto una postura o pedagogica o filosofica o didattica, ma un orientamento per l'insegnamentoapprendimento della filosofia dipende inizialmente dal punto di vista soggettivo adottato dal filosofo-docente; dalle condizioni strutturali, ad esempio, della scuola e dello spazio che consentiamo agli stessi studenti per il filosofare.

Keywords: Insegnamento di Filosofia. Scuola Secondaria di secondo grado. Filosofare. Aula. Scuola.

Acreditar no mundo significa principalmente suscitar acontecimentos, mesmo pequenos, que escapem ao controle, ou engendrar novos espaços-tempos, mesmo de superfície ou volume reduzidos.

(DELEUZE, 2013, p. 222)

\section{Introdução}

Com a disciplina Filosofia do Ensino de Filosofia do PROF-FILO (Núcleo da UERN/Campus Caicó-CaC), iniciamos uma viagem com o objetivo de discutir o ensino da filosofia na perspectiva de uma Filosofia do Ensino de Filosofia ${ }^{4}$, portanto, não numa abordagem pedagógica e didática, mas, filosófica e, consequentemente como fazer isso junto com os alunos do Ensino Médio.

A viagem iniciou a partir de um roteiro planejado e traçado. Nessa viagem, passamos por paisagens diferenciadas. A primeira paisagem foi a reflexão subjetiva sobre a seguinte questão: o que é filosofia para mim e como eu a ensino na Escola?5 Os múltiplos direcionamentos à pergunta "O que é a filosofia?” sugeridos por Martin Heidegger, Que é isto - a Filosofia? (2006); José

\footnotetext{
${ }^{4}$ A disciplina foi pensada inicialmente tomando como ponto de partida a conclusão apresentada por Velasco: "Cabe, pois, aos cursos de formação de professores de Filosofia, propiciar uma Filosofia do Ensino de Filosofia, tomando este ensino como problema e objeto de pesquisa da própria Filosofia". (VELASCO, 2014, p. 48).

${ }^{5}$ No sentido apontado por Tomazetti: "É necessário, pois, que se desenvolva, nos cursos de Filosofia, uma cultura de comprometimento com o ensino, que atrele o ensinar à formulação subjetiva de uma concepção de Filosofia". (TOMAZETTI, 2014, p. 33, grifo nossos).
} 
Ortega y Gasset, O que é Filosofia? (2016) e Gilles Deleuze e Félix Guattari, O que é a Filosofia? (2016) formam a segunda paisagem. Ao término do roteiro da viagem programada, enfrentamos momentos de dificuldades; desilusões; angústias; tempestades; momentos de recolhimento e também pregustamos alguns ingredientes favoráveis e prazerosos que nos foram propiciados. Nossa experiência, ao longo dessa jornada, foi extremamente desafiadora e exigiu que repensássemos nossas atitudes para tentarmos fazer filosofia na Escola. Com isso, colocamo-nos num caminho de do professor-filósofo que tenta reconstruir suas posturas e atividades filosóficas e se sente provocado no desafio de exercitar o filosofar na Escola.

\section{Primeira Paisagem}

Na primeira paisagem, ou seja, a partir da reflexão subjetiva sobre "o que é filosofia para mim e como eu a ensino na Escola?” surgiram vários questionamentos: Como penso a filosofia? Como valido a filosofia na sala de aula? O que eu quero verdadeiramente, formar alunos capazes de pensar filosoficamente ou alunos que conhecem por ouvir dizer algo da filosofia? Sou um informante da filosofia ou um professor-filósofo de filosofia? Ensino filosofia filosofando ou não? Considero-me um professor que ensina a história da filosofia, a cultura filosófica ou um filósofo-professor que propõe temas que levam os alunos a uma atitude filosófica? Como utilizo o livro didático de filosofia? Relaciono minha prática com alguma outra forma de ensino da filosofia? Essas questões foram levantadas nas primeiras discussões da disciplina Filosofia do Ensino de Filosofia no Mestrado Profissional em Filosofia (Núcleo da UERN/Campus Caicó) e serviram para direcionar as trocas de experiências entre os alunos do mestrado, professores do Ensino Médio. Além disso, essa primeira paisagem visava que cada um identificasse a concepção subjetiva de filosofia que subjazia à sua prática e como cada um se reconhecia nela como ensinantes de filosofia.

A partir dos questionamentos, percebemos que não é tarefa fácil ensinar filosofia na Escola na perspectiva de um ensino filosoficamente significativo para os sujeitos envolvidos na relação ensinante-aprendente. Mas, a ampla história da filosofia e, principalmente, seu caráter aberto e não 
dogmático, põe-nos a caminho da construção de sentidos frente aos problemas que se apresentam cotidianamente.

Nessa primeira paisagem, pensamos ainda a filosofia como a busca do 'porquê' e da causa das coisas serem como são. Por esse ângulo, a filosofia se apresentaria como investigativa, inconclusiva, reflexiva, crítica, questionadora e aberta aos mais variados temas que por ventura surjam num percurso sempre em construção. Entendemos a filosofia também como abertura ao diálogo. Uma oportunidade para construirmos juntos com os discentes uma ponte de relações que realmente faça sentido na vida própria de cada um. Nesse aspecto, buscamos incentivá-los a pensarem a própria existência, a vida, o mundo, a realidade, as relações culturais, sociais, éticas e políticas.

Além disso, pensamos que a filosofia é uma oportunidade que temos em sala de aula para levar nossos alunos a pensarem com mais afinco, fugir dos achismos e das opiniões infundadas. O ambiente escolar é propício para troca de experiências, para encontrar o outro, para construir e desconstruir e estreitar novos laços conceituais e práticos. É da natureza da filosofia desconfiar de tudo aquilo que parece óbvio e certo; é também da sua natureza fugir da comunicação fácil e rápida, dos preconceitos e de toda e qualquer realidade meramente aparente. Antes, a filosofia incomoda, desajeita, inverte a ordem das coisas e coloca professores e alunos na proximidade da verdade.

Esse é o ponto onde estamos, é o que temos buscado fazer, é o plano das intenções. Porém, nem sempre as coisas acontecem como desejamos. Talvez o resultado do produto não esteja saindo da forma almejada. Seguramente, vários alunos são afetados pelo fascínio que a filosofia exerce no processo de amadurecimento intelectual e humano, mas os frutos nem sempre serão o esperado porque no decorrer do ano letivo a estrutura e o ambiente escolar, muitas vezes, não facilitam esse processo, assim como não conseguimos manter a mesma intensidade em todas as aulas. ${ }^{6}$ Além do mais, fazer filosofia filosofando não é tarefa simples, exige-nos mais conhecimento e maturidade filosófica.

\footnotetext{
${ }^{6}$ De acordo com Silva "A escola é o lugar em que todas as dimensões da realidade se refletem, mas é fato também que, durante muito tempo, ela foi vista quase essencialmente como lugar de adestramento, onde ao aluno cabia apenas o 'direito' e o dever de aceitar, assimilar e reproduzir o que quer que fosse. Excluiu-se da escola o pensar, o refletir para agir, tão específico da raça humana, e promoveu-se a imitação, a cópia e o 'engessamento' daquele que, teoricamente, a frequentava com intuito de conhecer e crescer em todos os aspectos do contexto pessoal e social". (2014, p. 203).
} 


\section{Segunda Paisagem}

No roteiro de viagem traçado, já em percurso, deparamo-nos com uma paisagem composta de três elementos. $O$ primeiro que relataremos suscintamente, é Que é isto - a Filosofia? (2006) de Martin Heidegger (18891977)7. Para ele, “o diálogo é conduzido a um caminho. Digo: a um caminho. Assim concedemos que este não é o único caminho" (HEIDEGGER, 2006, p. 15). Ao se apresentar um caminho, necessariamente se deve insinuar onde esse pode nos levar. Aqui sugerimos um aspecto da filosofia de Martin Heidegger que pareceu-nos interessante para a compreendermos tendo em vista a filosofia e o seu ensino:

O fenômeno é o que está implícito em tudo aquilo que se manifesta mas, em geral é menosprezado, não olhado de frente, por assim dizer, e é tarefa da filosofia retirá-lo do esconderijo. Ora, o fenômeno por excelência é o ser (ROVIGHI, 2011, p. 398-399).

Clarear as coisas é a tarefa do filósofo; trazer à tona o que se esconde por trás do fenômeno. Feito essa observação, ancoramos nosso entendimento sobre essa obra específica de Heidegger em três aspectos discutidos na disciplina Filosofia do Ensino de Filosofia: correspondência, disposição e pathos.

O ponto de partida sugerido por Heidegger é a existência de um interlocutor: o pensamento grego e o diálogo com a tradição. Discutir Heidegger nos levou a perceber que só somos capazes de filosofar, no momento em que nos colocamos no caminho da cor-respondência, da disposição e do pathos (espanto). Vivemos na cor-respondência na medida em que conseguimos operar junto com alguém, filosofar junto com ele. Filosofia seria num primeiro instante correspondermos com a tradição. O corresponder está numa disposição que representa o fato de estarmos abertos para que algo de fato seja, de que o dizer se funda na escuta do apelo. A disposição é uma abertura à correspondência. E, por fim nos defrontamos com o pathos que

\footnotetext{
${ }^{7}$ Para uma introdução ao problema da educação em Martin Heidegger indicamos o número especial da revista APRENDER - CADERNOS DE FILOSOFIA E PSICOLOGIA DA EDUCAÇÃO. Especial: Heidegger e a Educação Ano VI, No 10, jan./jun. Disponível em: http://periodicos.uesb.br/index.php/aprender/issue/view/171). Acesso em 30 set. 2019. De modo especial, sugerimos a leitura do artigo: ANDRADE, Duarte de. Heidegger educador. APRENDER - Cad. de Filosofia e Pisc. da Educação. Vitória da Conquista Ano VI n. 10 p. 57-72 2008. Disponível em: http://periodicos.uesb.br/index.php/aprender/article/viewFile/4193/ pdf 205. Acesso em 30 set. 2019. Esse artigo diz mais do que aquilo que vimos nos elementos dessa paisagem heideggeriana.
} 
traduzido por espanto, é facilmente considerado, para uma parte da tradição filosófica ${ }^{8}$ o archè da Filosofia. Assim, cor-responder é um falar e a linguagem está a serviço do pensamento e o pensamento da linguagem (HEIDEGER, 2006).

Mas qual relação se dá entre esse pensamento de Heidegger e a nossa compreensão do que seja a filosofia? Heidegger nos coloca em um caminho. É mais um caminho em busca de uma aproximação do que seja a filosofia. O caminho sugerido por Heidegger passa pela correspondência, pela disposição e pelo espanto. Mas, não correspondemos caminhando os mesmos passos e repetindo o caminhar. Corresponder, como o entendemos, não pode ser repetir, mas a correspondência exigiria que abríssemos novas veredas e outras trilhas e caminhássemos também por caminhos ainda não caminhados. Pensamos que ensinar filosofia na Escola, nesse sentido, poderia nos levar a correspondemos à tradição filosófica. Entendemos, rompendo um pouco com a proposta de Heidegger, que não precisamos nem necessitamos corresponder apenas à tradição grega, pois nos parece necessário também caminhar e caminhar juntos com os alunos por outras tradições de pensamento?.

Um segundo elemento ou aspecto dessa segunda paisagem, foi o encontro com O que é Filosofia? (2016), de José Ortega y Gasset (1883-1955) ${ }^{10}$. $\mathrm{Na}$ sua crítica ao realismo (ser $=$ mundo) idealismo $($ ser $=$ sujeito), o filósofo espanhol aponta para um novo achado, para uma "nova realidade radical" para a qual não servem "os conceitos tradicionais de realidade e de ser" (2016, p. 209). Talvez aqui possamos esboçar com Ortega y Gasset traços de uma

\footnotetext{
${ }^{8}$ A origem da filosofia, nos versos cordelísticos do poeta e professor-filósofo Lindoaldo Campos: "Vem da admiração / Espanto/deslumbramento / Pelos mistérios do mundo / Em busca de fundamento / É um renascer constante / Que alguns sentem diante / Da vida em seu movimento" (Filosofia: o que é isso?, p. 04). Noutro verso o poeta assim poetiza: "O que devemos fazer? / Há destino ou liberdade? / A vida tem um sentido? / O que é mal e bondade? / Filosofia vem, portanto / do thaumazéin, o espanto / Perante a realidade". (Espanto: o começo de tudo, p. 03). Por sua vez, Gallo e Kohan afirmam que "[...] nem todos os filósofos gregos foram aristocratas e nem todos os filósofos aristocratas gregos filosofaram movido pelo espanto". Depois afirmam que "Nos dias de hoje [sociedade do espetáculo] o espanto é mais um objeto de consumo, preso às leis do mercado, do que a expressão de uma subjetividade privilegiada admirada perante o espetáculo do mundo" (GALLO; KOHAN, 2000, p. 186; 187).

${ }^{9}$ Pensamos aqui, por exemplo, na filosofia latino-americana e africana. Para uma melhor crítica a Heidegger no horizonte da questão "O que é a metafísica?”, ver: Deleuze e Guatarri (2016, p. 113-125).

${ }^{10}$ Para uma introdução à questão da educação em Ortega y Gasset: CARINO, Jonaedson. Ortega y Gasset e o problema da educação. Fórum educ. Rio de Janeiro, 12 (1) 35-50, jan./mar. 1988; DORNAS, Danilo Santos. O problema da educação na filosofia da razão vital de Ortega y Gasset. APRENDER - Cad. de Filosofia e Pisc. da Educação. Vitória da Conquista Ano II n. 2 p. 47-57 2004.
} 
pedagogia do conceito $^{11}$ : um primeiro passo é aceitar que apesar de inadequados, os conceitos tradicionais continuam sendo usados, pois “[...] antes de descobri-lo e ao descobri-lo não temos outro"; em segundo lugar, "para formamos um conceito novo, antes precisamos ter e ver algo novíssimo" (ORTEGA Y GASSET, 2016, p. 209-2010).

No caso específico do filósofo espanhol, o novo que se descortina é o "viver":

Para os antigos, a realidade, ser, significava 'coisa'; para os modernos, ser significava 'intimidade, subjetividade', para nós, ser significa 'viver' - portanto, intimidade consigo e com as coisas. Confirmamos ter chegado a um nível espiritual mais alto porque, se olhamos para os nossos pés, para o nosso ponto de partida - o viver -, vemos que nele estão conservadas, integradas uma à outra e superadas, a antiguidade e a modernidade. Estamos num nível mais algo - estamos no nosso nível -, estamos à altura dos tempos. (ORTEGA Y GASSET, 2016, p. 210).

Em terceiro lugar, se o que temos e vemos é "algo novíssimo", então nos damos conta de que "Não nos servem os conceitos e categorias da filosofia tradicional - de nenhuma delas”. Assim, em quarto lugar, para Ortega é nossa tarefa e dever "conceber o que vemos com conceitos novos". Mais ainda, não é só uma tarefa, mas uma "sorte" só comparada a dos gregos:

Senhores, cabe a nós a sorte de estrear conceitos. Por isso, desde a nossa presente situação, compreendemos muito bem a delícia que os gregos devem ter sentido. São os primeiro homens a descobrir o pensar científico, a teoria - essa especialíssima e engenhosa carícia que a mente faz nas coisas, amoldando-se a elas numa ideia exata. Não tinham um passado científico às suas costas, não tinham recebido conceitos já feitos, palavras técnicas consagradas. Tinham diante de si o ser que haviam descoberto e à mão só a linguagem usual - 'O português claro' - e, de repente, acontecia de uma das humildes palavras cotidianas se encaixar prodigiosamente naquela importantíssima realidade que tinham à frente. A palavra humilde ascendia, como por levitação, do plano vulgar da prosa, da conversa, e se envaidecia nobremente em termo técnico, se orgulhava como o palafrém do peso de soberana ideia, que oprimia suas costas. Quando se descobre um novo mundo, as palavras necessárias arcam com grandes fortunas. (ORTEGA Y GASSET, 2016, p. 215, grifo nossos).

\footnotetext{
${ }^{11}$ Aqui não cabe explicitar a diferença entre a compreensão de Ortega y Gasset e aquela de Deleuze/Guatarri sobre o "conceito". Porém, cabe dizer apenas que utilizamos o termo "pedagogia do conceito" influenciados por Deleuze e Guatarri (2016, p. 18): "Os pós-kantiano giravam em torno de uma enciclopédia universal do conceito, que remeteria sua criação a uma pura subjetividade, em lugar de propor uma tarefa mais modesta, uma pedagogia do conceito, que deveria analisar as condições de criação como fatores de momentos que permanecem singulares".
} 
Um quinto e último aspecto dessa "pedagogia do conceito" que temos tentado esboçar nesse texto de Ortega y Gasset (2016) refere-se às palavras que dizem o conceito. Na citação anterior, o filósofo espanhol já nos dá indicações: "a linguagem usual"; "humildes palavras cotidianas"; "a palavra humilde" e "as palavras necessárias”. Na página seguinte Ortega y Gasset (2016, p. 2016) fala de "vocabulário trivial"; "palavra sem classe, sem passado científico" e "uma pobre voz vernacular". O que acontece entre a palavra e o conceito é descrito como um movimento de descida da ideia à palavra: a ideia desce como chama sobre a palavra trivial ou a palavra pobre se incendeia com a luz da ideia e se torna um termo técnico. Para Ortega y Gasset o uso da palavra trivial e pobre "[...] é um sintoma a mais de que a sorte nos favoreceu e que chagamos pioneiros e novos a uma coisa intacta" (ORTEGA Y GASSET, 2016, p. 216).

Por fim, o último aspecto dessa pedagogia, mas não o sexto, mas um que resume e a partir do qual podemos nos apropriar da proposta de Ortega y Gasset está expresso nas seguintes palavras (2016, p. 231): “Superar é herdar e acrescentar". Já citamos anteriormente que no "viver" “[...] estão conservadas, integradas uma à outra e superadas, a antiguidade e a modernidade" (2016, p. 210). Nesse sentido, superar a antiguidade e a modernidade só é possível na medida em que a antiguidade e a modernidade também são conservadas, ou seja, o passado é transposto na medida em que negado e assassinado, mas também ressuscitado e revivido pelo "espírito": matar, negar e nisso mesmo continuar a superar o passado:

Superar é herdar e acrescentar. Quando digo que necessitamos de conceitos novos, refiro-me ao que temos de acrescentar - os velhos perduram, mas com um caráter subalterno. Se nós descobrimos um novo modo de ser mais fundamental, é evidente que necessitamos de um conceito de ser desconhecido antes - mas, ao mesmo tempo, esse nosso conceito novíssimo tem a obrigação de explicar os antigos. (ORTEGA Y GASSET, 2016, p. 231).

A partir dessas considerações, chegamos à conclusão de que, primeiro, o ensino da filosofia deve se dar na necessária referência ao passado, não temos que "começar de novo", mas devemos nos considerar "herdeiros". Porém, segundo, essa herança sempre deve ser negada em nome de algo que temos e vemos como "novíssimo". Terceiro, para dizer o "novo" não servem mais os conceitos e as categorias tradicionais, daí a tarefa de conceber e a sorte de estrear novos conceitos. Quarto, para dizer os novos conceitos não são 
necessárias novíssimas palavras, mas podemos utilizar a palavra mais trivial, mais vulgar, mais humilde ${ }^{12}$.

O novo que se descortinou para Ortega y Gasset foi o "viver". “[...] viver é encontrar-me no mundo" (2016, p. 236) e "encontrar-se ocupado com algo do mundo. Eu consisto num ocupar-me com o mundo, e o mundo consiste em tudo aquilo de que me ocupo e em nada mais" (2016, p. 241). Com que se ocupa o filósofo? Com o que se ocupa o filósofo-professor? Para responder a essas questões é necessário diferenciar a "doutrina filosófica" do "ser da filosofia". Segundo Ortega y Gasset até o momento, ou seja, a décima primeira e última aula proferida no dia 17 de maio de 1929, à resposta mais radical à pergunta "o que é filosofia?" ainda não tinha sido feita, porque havia definido nas aulas anteriores "o que é a doutrina filosófica" e teria avançado nela "até encontrar a vida". De modo mais preciso, ele assim afirma: "[...] a doutrina filosófica, isso que está ou pode estar em livros, é só a abstração da autêntica realidade 'filosofia' - é só seu resquício e seu corpo semimorto. [...] o ser da filosofia é o que faz o filósofo; o filosofar é uma forma do viver”. E, algumas linhas abaixo, conclui que "Tudo o que não seja definir a filosofia como filosofar e o filósofo como um tipo essencial de vida é insuficiente e não é radical" (ORTEGA Y GASSET, 2016, p. 244).

Mais uma vez, e a partir desses segundos elementos e aspectos da segunda paisagem, pensamos na nossa vida como filósofo-professor de filosofia na Escola. Em primeiro lugar, compreendemos que no ensino da filosofia não podemos negar que somos herdeiros e, portanto, não podemos ensinar filosofia sem recorrer à tradição filosófica. Contudo, o recurso à tradição é para nega-la e supera-la, pois a doutrina dos filósofos é "sobra" daquilo que mais radicalmente é a filosofia. A superação da herança deve acontecer na aparição do novo, do novíssimo que temos e vemos. Se o ensino da filosofia na Escola deve ser filosófico e se o filosofar é uma forma de viver e, por isso mesmo, de estar no mundo, precisamos juntos com os alunos esperar, estar abertos a encontrar o novo num mundo em que quase tudo se

\footnotetext{
12 Fazemos referência aqui a uma frase de Deleuze não para comparar os autores, mas apenas para referir esse elemento importante entre o conceito e a palavra que o diz: "Às vezes censuramo-nos por empregarmos palavras complicadas a fim de 'parecer chique'. Isso não é maldoso, é idiota. Um conceito ora necessita de uma nova palavra para ser designado, ora se serve de uma palavra ordinária à qual dá um sentido singular”. (DELEUZE, 2013, p. 46).
} 
repete, se replica e se espalha em um click. Nesse sentido, concordamos com Tomazetti quando afirma que:

[...] não ensinamos apenas 'conteúdos', ideias, informações, conceitos, sistemas, mas desejamos ensinar um gesto, uma relação, uma atitude filosófica. Não se trata de ensinar apenas um discurso filosófico, mas também um modo de vida filosófico. (TOMAZETTI, 2013, p. 42).

Chegamos ao terceiro elemento da segunda paisagem: Deleuze e Guattari com a obra O que é a Filosofia? (DELEUZE; GUATARRI, 2016) ${ }^{13}$ e lá encontramos a seguinte inscrição: “talvez só possamos colocar a questão 'O que é Filosofia?' tardiamente, quando chega a velhice, e a hora de falar concretamente. [...] enfim: mas o que é isso que fiz toda a minha vida?”. Em seguida, define a filosofia como "a arte de formar, de inventar, de fabricar conceitos" e, "criar conceitos sempre novos é o objeto da filosofia" (DELEUZE; GUATTARI, 2016, p.7; 8; 11)..$^{14}$

Dessa forma, adentramos a sua proposta que é a construção e a invenção do conceito. Ora, se para eles a filosofia é criação e invenção dos conceitos, então, ela não pode ser nem contemplação, nem reflexão e nem comunicação. Os nossos autores elaboram uma proposta a partir do plano da imanência e o papel do filósofo é mergulhar no caos. É importante dizer também, que os planos de imanência são os mais variados possíveis porque as épocas são diferentes e experimentamos o devir. ${ }^{15}$

\footnotetext{
${ }^{13}$ Não pretendemos aqui trazer novidades sobre esse modo de pensar a filosofia e sobre como pensar a partir daí o seu ensino no Ensino Médio. De modo geral, sobre a relação entre Gilles Deleuze e a educação citamos dois textos: KOHAN, Walter Omar. Entre Deleuze e a educação: notas para uma política do pensamento. Educaşão e Realidade. 27 (2): 123-130 jul./dez. 2002. GALLO, Silvio. Deleure \& a Educação. Belo Horizonte, MG: Autêntica, 2003. Nesse último texto, o autor retoma e "desloca" alguns temas deleuzianos e os aproxima da filosofia da educação e do ensino de filosofia. Portanto, em nosso texto, resta-nos descrever o que vimos quando olhamos para esses elementos deleuzianos.

${ }^{14}$ Em Conversações Deleuze retoma a questão: "Volto à questão: o que é a filosofia? Porque a resposta a essa pergunta deveria ser muito simples. Todo mundo sabe que a filosofia se ocupa de conceitos. Um sistema é um conjunto de conceitos. Um sistema é aberto quando os conceitos são relacionados a circunstâncias, e não mais a essências. Mas, por um lado, os conceitos não são dados prontos, eles não preexistem: é preciso inventar, criar conceitos, e nisso há tanta criação e invenção quanto na arte ou na ciência. Criar novos conceitos que tenham uma necessidade, sempre foi essa a tarefa da filosofia. É que, por outro lado, os conceitos não são generalidades à moda da época. Ao contrário, são singularidades que reagem sobre os fluxos de pensamento ordinários: pode-se muito bem pensar sem conceitos, mas dedes que haja conceito há verdadeiramente filosofia". (DELEUZA, 2013, p. 45-46).

${ }^{15}$ Para Huisman "[...] é de si mesmo que o filósofo extrai a necessidade de criar novos conceitos, e é da reorganização interna de seu próprio pensamento que ele extrai essa substância. Assim, a filosofia nasce efetivamente na Antiguidade, na Grécia, mas esse quadro histórico, social e cultural não passa de prévia para a constituição do plano de imanência, espécie de fundo urdido por esses autores-encenadores que são os filósofos, à frente do qual o teatro conceitual é representado. 'Para que a filosofia nascesse, foi preciso um encontro entre o
} 
Ao olhar para esses elementos, pensamos um pouco sobre os impactos dessa filosofia para o Ensino Médio, encontramos o termo "resistência" (DELEUZE; GUATTARI, 2016) ${ }^{16}$. A filosofia precisa incentivar os alunos a resistirem. É preciso resistir àquilo “[...] que é uma ofensa ao pensamento” (DELEUZE, 2013, p. 46). Para Deleuze os ofensores são os regimes político, cultural e jornalístico. Assim, é preciso resistir com os alunos ao tempo presente que corre em alta velocidade; compreender e denunciar alguns processos políticos e econômicos como a globalização, o capitalismo etc. É preciso resistir ao exagero de informação que gera acúmulo de opiniões vazias que nos conduzem ao caos. Com a resistência, buscaríamos criar com os alunos um conceito novo que suscite um novo devir. O filósofo mergulha no caos e busca o conceito.

Afirmam Deleuze e Guatarri:

Se a filosofia se reterritorializa sobre o conceito, ela não encontra sua condição a forma presente do Estado democrático, ou num cogito de comunicação mais duvidoso ainda que o cogito da reflexão. Não nos falta comunicação, ao contrário, nós temos comunicação demais, falta-nos criação. Falta-nos resistência ao presente. (DELEUZE; GUATARRI, 2016, p. 130, grifo dos autores)

Dessa forma, ensinar filosofia na educação básica seria traçar o plano de imanência, identificar o que acontece e trabalhar junto com os alunos a necessidade de resistirmos aos doutrinamentos que possam surgir. Com a filosofia, a Escola seria o espaço em que seria possível disponibilizar tempo. O espaço/tempo escolar seria o momento oportuno para o mergulho no que acontece e, assim, com o conceito, criar um modo de resistência contra toda e qualquer tentativa de ideologia que por ventura tenha como intenção limitar os horizontes de compreensão da realidade, da vida, da sociedade, da cultura e da política.

meio grego e o plano da imanência do pensamento'. Motivo pelo qual, se for preciso escolher entre a história e sua razão determinante e a geografia e sua razão contingente, Deleuze e Guattari optam por esta última, e explicam o nascimento da filosofia, o que os leva a construir uma 'geofilosofia'. O filósofo geógrafo visitará assim os territórios da filosofia, não para procurar a Razão na história, como fazia Hegel, mas como o viajante que Nietzsche propunha constituir o duplo ou a sombra do filósofo". (HUISMAN, 2000, p. 409).

16 Após afirmar que "O conceito de resistência deve ser compreendido sempre no âmbito das relações de poder, [...]", Tomazetti relaciona a "resistência" com o ensino da filosofia: "Penso resistimos quando ficamos à espreita, à espera de oportunidades ou mesmo construímos tais oportunidades; resistimos quando insistimos em ensinar e tentar ensinar Filosofia como experiência de pensamento. De forma mais explícita: resistimos quando nos recusamos a permanecer na ordem da explicação, da exposição do foi produzido pelos filósofos e que compõe a tradição filosófica". (TOMAZETTTI, 2013, p. 46). 
Deveríamos construir nas Escolas um ambiente favorável, onde docentes e discentes fossem capazes de construir em suas vidas algo que realmente fizesse sentido e tivesse significado no tocante à existência e seus mais variados aspectos. A filosofia, portanto, seria nessa visão, um eterno devir.

\section{Considerações Finais}

Enfim, estamos nos aproximando do término da nossa viagem. A inquietude que nos toma conta no momento é aquela de repensar a filosofia no Ensino Médio, haja vista nossa compreensão subjetiva do que seja a filosofia (primeira paisagem) e os vários elementos observados no caminho da Filosofia do Ensino de Filosofia (elementos da segunda paisagem). Nesse trajeto, deparamo-nos com momentos de escuridão e claridade, tempestade e calmaria, porque a discussão em torno da "Filosofia do Ensino de Filosofia" tem sido aquela de nos colocar frente ao nosso fazer filosofia no Ensino Médio. Nessa viagem, pensamos mais o nosso modo de ensinar filosofia do que qualquer outra coisa. Esse fato, acreditamos ser o mais relevante de toda a jornada. Ele nos põe numa perspectiva de exercitar o pensamento, trazendo-nos algo novo, um acontecimento capaz de construir ou reconstruir nossa maneira de trabalhar a filosofia no ambiente escolar.

Ao final do roteiro da viagem, percebemos que o momento foi mais de vislumbres, ideias, boa vontade e questionamentos do que propriamente de tomada de decisões já agora. Esperamos que ao término desse processo, tenhamos edificado com mais lucidez o caminho que começamos a percorrer há anos e a meta seja aquela de buscarmos desde o primeiro momento filosofar. Vários são os questionamentos, dentre eles destacamos alguns: estamos realmente filosofando em sala de aula? Conseguimos estimular os discentes a atrever-se a pensar filosoficamente? É correto institucionalizar a filosofia? Será que cobramos uma postura dos nossos alunos quando de fato nem nós mesmos filosofamos? Ao fazer essas interrogações, encontramos em Cerletti (2008, p. 81), o seguinte pensamento: "Filosofar depende, em última instância, de uma decisão subjetiva, e não apenas em relação ao querer ser filósofo, mas porque supõe colocar em ato um pensamento e isto implica a novidade de quem o tenta". 
Os elementos da segunda paisagem que aqui foram descritos são perspectivas, sem que tenhamos que fixar o olhar em apenas um deles, em alguns deles ou em todos eles. Com a filosofia, enquanto professores-filósofos, devemos criar a nossa própria relação e partir daí sermos capazes de filosofar. Talvez essa seja a nossa maior angústia, ter o filosofar como modo de vida que levamos para a sala de aula. Com relação a essas reflexões anteriores, pensamos com Cerletti (2008, p. 8) que “o ensino da filosofia é basicamente, uma construção subjetiva, apoiada em uma série de elementos objetivos e conjunturais. Um bom professor de filosofia [...] será aquele que possa levar adiante, de forma ativa e criativa, essa construção". A essa proposta acrescentaríamos que ela obteria mais êxito se conseguíssemos tomar o filosofar e levar nossos alunos a filosofarem, ou seja, essa forma ativa e criativa deveria "sobrevoar" o campo dos conteúdos, das pedagogias e das didáticas para que "Ensinar filosofia [fosse] dar um lugar ao pensamento do outro" (CERLETTTI, 2008, p. 87).

Portanto, conforme o título do nosso trabalho - Exercícios de pensamento para não sermos indiferentes ao que fazemos em nome da filosofia na escola ${ }^{17}$ - chegamos à conclusão de que não existe a melhor forma de se fazer filosofia e filosofar na Escola, mas, com a filosofia, no chão da Escola sempre somos lançados em mar aberto. Ensinar filosofia é um desafio no qual nunca se tem um porto seguro, como bem disse Leibniz: “eu acreditava entrar no porto, mas... fui jogado novamente em pleno mar" (DELEUZE e GUATTARI, 2016, p. 30, apud LEIBNIZ, p. 12).

\section{Referências bibliográficas}

ANDRADE, Pedro Duarte de. Heidegger educador. APRENDER - Cad. de Filosofia e Psic. da Educação. Vitória da Conquista. Ano VI n. 10 p. 57-72, 2008. Disponível $<$ http://periodicos.uesb.br/index.php/aprender/article/viewFile/4193/ pdf 205>. Acesso em 21.09.2017.

\footnotetext{
${ }^{17}$ Duas notas nota sobre o título do artigo: a) "Pensar é experimentar, mas a experimentação é sempre o que se está fazendo [...]” (DELEUZE; GAUTARRI, 2016, p. 133); b) "Precisamos elaborar uma perspectiva, uma proposta, uma saída que brote de nossos encontros com a Filosofia, que nasça de nossa própria relação com ela. É sempre necessário, então, recolarmos a pergunta de Walter Kohan (2002): o que corremos o risco de fazer em nome da Filosofia nas escolas de Ensino Médio?” (TOMAZETTT, 2013, p. 42).
} 
CAMPOS, Lindoaldo. Filosofia: o que é isso? Origem - Fundamentos - Periodos Temas - Pensadores. Editor: Israel Maria dos Santos Segundo. Diagramação: Agostinho Francisco dos Santos (Coleção Filosofia em Cordel no ${ }^{\circ}$ 1).

Espanto: o começo de tudo. Os filósofos pré-socráticos. Editor: Israel Maria dos Santos Segundo. Diagramação: Agostinho Francisco dos Santos (Coleção Filosofia em Cordel n. 2).

CARINO, Jonaedson. Ortega y Gasset e o problema da educação. Fórum educ. Rio de Janeiro, 12 (1) 35-50, jan./mar. 1988.

CERLETTI, Alejandro. O ensino de filosofia: como problema filosófico. Belo Horizonte: Autêntica, 2009.

DELLEUZE, Gilles; GUATTARI, Félix. O que é Filosofia? Rio de Janeiro: Editora 34, 2016.

Conversações. Tradução de Peter Pál Pelbart. $3^{a}$ Edição. São

Paulo: Editora 34, 2013, 160

DORNAS, Danilo Santos. O problema da educação na filosofia da razão vital de Ortega y Gasset. APRENDER - Cad. de Filosofia e Pisc. da Educação. Vitória da Conquista Ano II n. 2 p. 47-57 2004.

GALLO, Silvio; KOHAN, Walter Omar. Crítica de alguns lugares-comuns ao se pensar a filosofia no ensino médio. In: GALLO, Silvio; KOHAN, Walter Omar. Filosofia no ensino médio. Petrópolis, RJ: Vozes, 2000, p. 174-196.

GALLO, Silvio. Deleuze \& a Educação. Belo Horizonte, MG: Autêntica, 2003.

HEIDEGGER, Martin. Que é isto - a Filosofia? Petrópolis-RJ: Vozes, 2006.

HUISMAN, Denis. Dicionário de obras filosóficas. São Paulo-SP: Martins Fontes,2000.

KOHAN, Walter Omar. Entre Deleuze e a educação: notas para uma política do pensamento. Educação e Realidade. 27 (2): 123-130 jul./dez. 2002.

ORTEGA Y GASSET, José. O que é Filosofia? Campinas-SP: Vide Editorial, 2016.

SILVA, Sônia Sena da. Estudos filosóficos no ensino básico: Quem se habilita a ministrar essas aulas? In: MATOS, Junot Cornélio; COSTA, Marcos Roberto Nunes (Orgs). Ensino de filosofia: questões fundamentais. Recife: Editora UFPE, 2014.

TOMAZETTI, Elisete M. Filosofia como disciplina: entre a instituição, a vigilância e o pensar filosófico. In: SÁ JÚNIOR, Lucrécio Araújo de; BIELLA, Jaime. (Organizadores). Filosofia no ensino médio: desafios e perspectivas. Natal, RN: Edufrn, 2013, p. 37-49. 
Formação de Professor de Filosofia para o Ensino Médio: entre políticas e práticas, entre universidade e escola. In: MATOS, Junot Cornélio; COSTA, Marcos Roberto Nunes. Ensino de Filosofia: questões fundamentais. Recife: Ed. Universitária UFPE, 2014, p. 31-42.

VELASCO, Patrícia Del Nero. Possibilidades e perspectivas para o Ensino de Filosofia no Ensino Médio: um olhar a partir dos cursos de formação de professores. In: MATOS, Junot Cornélio; COSTA, Marcos Roberto Nunes. Ensino de Filosofia: questões fundamentais. Recife: Ed. Universitária UFPE, 2014, p. 43-54. 